TUMOUR necrosis factor (TNF) inhibits the accumulation of acetyl CoA carboxylase (ACC) mRNA by decreasing the rate of ACC gene transcription. The ACC mRNA species found in $30 \mathrm{~A} 5$ cells are generated from promoter II and TNF inhibits the accumulation of class 2 type mRNAs. By using $5^{\prime}$ deletion mutants of promoter II fused to the bacterial chloramphenicol acetyltransferase (CAT) gene, the DNA mobility shift assay and the DNase I footprinting assay, the authors have identified the $30 \mathrm{bp}$ from -389 to -359 as the TNF responsive element in promoter II. TNF treatment causes a decrease in the binding activity of nuclear protein(s) specific to the TNF responsive element. When the fragment containing the TNF responsive element was incorporated into the thymidine kinase promoter, the chimeric gene exhibited TNF induced inhibition of expression.

Key words: Acetyl CoA, Gene transcription, mRNA, Tumour necrosis factor

\section{Sequences of acetyl CoA carboxylase promoter for tumour necrosis factor action}

\author{
Keerang Park, Michael E. Pape and Ki-Han \\ Kim $^{\text {CA }}$
}

Department of Biochemistry, Purdue University, West Lafayette, IN 47907, USA

${ }^{\mathrm{CA}}$ Corresponding Author

\section{Introduction}

The presence of a chronic infection or malignancy induces macrophages to produce TNF and subsequently drives bodily metabolism towards a constitutive catabolic state, the primary characteristic of cachexia. A hallmark of cachexia is the depletion of lipid reserves from adipocytes and the accumulation of serum lipids. ${ }^{1}$ Oliff and co-workers have demonstrated that nude mice harbouring solid tumours which secrete TNF display 'cancerassociated cachexia'. These mice show a marked loss of intrascapular fat pads, perirenal and subcutaneous fat. Although it is difficult to directly assess the role of TNF in altering fat depots and inducing cachexia in this animal model, ${ }^{2,3}$ it is apparent that TNF has a marked effect on lipid metabolism. This is also borne out in other systems. $^{4-7}$

TNF completely inhibits the conversion of 3T3-L1, TA1 and 30A5 preadipocytes to adipocytes in in vitro culture systems. ${ }^{4-7}$ In addition, TNF can also induce fully differentiated adipocytes to revert to a preadipocyte like state under certain culture conditions. ${ }^{6-8}$ The aim of this work has been to understand how TNF alters lipid metabolism by studying the effect of the monokine on acetyl CoA carboxylase gene expression in $30 \mathrm{~A} 5$ preadipocytes.

Acetyl CoA carboxylase (ACC) catalyzes the rate-limiting step in the biosynthesis of long-chain fatty acids. ${ }^{9}$ It has been shown that TNF completely inhibits the conversion of $30 \mathrm{~A} 5$ preadipocytes to adipocytes with the concomitant inhibition of the accumulation of ACC mRNA.,10 TNF suppresses ACC mRNA accumulation by decreasing the rate of transcription of the ACC gene. ${ }^{10}$ ACC mRNA exists in multiple forms which are generated as a result of differential splicing of two primary transcripts of two distinct promoters, promoters I and II. ${ }^{11,12}$ Expression of these promoters is tissue specific and dependent upon physiological conditions. In the case of $30 \mathrm{~A} 5$ cells, the primary gene products are those mRNAs produced under the influence of promoter II, and there is little or no ACC mRNA from promoter $\mathrm{I}^{13}$ In this paper, the promoter II region of the ACC gene which confers TNF responsiveness to the gene has been characterized. The authors show that a $30 \mathrm{bp}$ fragment in the $5^{\prime}$ flanking sequences of the ACC gene confers TNF mediated inhibition of transcription. In addition, evidence that specific binding of nuclear proteins to the $30 \mathrm{bp}$ fragment is decreased upon treatment of $30 \mathrm{~A} 5$ cells with TNF, is presented.

\section{Materials and Methods}

Materials: The following commercial products were used: Eagle basal medium (MA Bioproducts, Walkersville, MD); foetal bovine serum (GIBCO Laboratories, Grand Island, NY); dexamethasone and insulin (Collaborative Research, Inc., Waltham, MA); T4 DNA polynucleotide kinase, restriction enzymes (New England Biolabs, Beverly, MA); DNA polymerase Klenow fragment, DNase I, exonuclease III, and calf intestinal alkaline phosphatase (Boehringer Mannheim, Indianapolis, IN); ${ }^{14} \mathrm{C}$-labelled chloramphenicol, $\left[\gamma^{32} \mathrm{P}\right]$-adenosine $5^{\prime}-$ triphosphate (Amersham, IL); recombinant human 
TNF- $\alpha\left(2.7 \times 10^{7} \mathrm{U} / \mathrm{mg}\right)$ was generously provided by Dr Tatsuro Nishihara of the Suntory Institute, Osaka, Japan.

Cell culture: The $30 \mathrm{~A} 5$ preadipocyte cells were grown in Eagle basal medium containing 10\% foetal bovine serum or bovine calf serum (Hyclone, Logan, UT) as described previously. ${ }^{14}$ TNF included in the medium at a concentration of $200 \mathrm{U} / \mathrm{ml}$, from day 0 (the day of confluence, D-0) prevents differentiation under two differentiation schemes. ${ }^{14}$ These cells are called TNF treated preadipocytes.

Plasmid constructions: Construction of the plasmids, pUC-CAT3 and plasmid pPII-CAT0 has been described previously. ${ }^{12}$ The plasmid pPII-CAT0 contains the -994 to +62 (relative to the first transcription initiation start site) region of promoter II in a $5^{\prime}$ to $3^{\prime}$ orientation relative to the CAT gene. The exonuclease III method and standard recombinant DNA techniques ${ }^{15}$ were used to generate a series of $5^{\prime}$ deletion mutants of ACC promoter II. The end point and orientation of the deletions were determined by DNA sequencing. ${ }^{15}$

Putative regulatory elements were placed into a thymidine kinase (TK)/CAT fusion gene. p'TK-CAT ${ }^{12}$ which contains the $-109 /+51$ region of the TK promoter distal to the CAT gene was digested at the unique $S a l I$ site and filled in. Various fragments of ACC promoter II, as indicated in the text, were blunt-end ligated into this site.

The synthesized mouse TNF responsive sequence spanning -370 to -340 was flanked by SacI restriction sites and used for cloning. These oligonucleotides are as follows:

5'-GGTGGAGGTTGGCCGGCCCAAACCCGCCTAGCT- ${ }^{\prime}$, and 5'-AGGCGGGT'T'TGGGCCGGCCAACCTCCACCAGCT-3'. The synthesized complementary strands were annealed, phosphorylated by T4 polynucleotide kinase and ligated into pPII-CAT4 plasmid vector which was digested with $S a c$ I restriction enzyme and dephosphorylated with calf intestinal alkaline phosphatase. All constructed mutants were confirmed by DNA sequencing. ${ }^{15}$ The features of all gene constructs used are shown in Fig. 1.

Transfections and CAT assays: Cell monolayers at $80-90 \%$ confluence were transfected with $20 \mu \mathrm{g}$ of ACC-CAT construct DNA by coprecipitation with calcium phosphate. ${ }^{16}$ Cells were exposed to the precipitate for $8 \mathrm{~h}$ at which time fresh medium with or without $200 \mathrm{U} / \mathrm{ml}$ of TNF was added. Cell lysates were made $60 \mathrm{~h}$ later by sonication in $150 \mu \mathrm{l}$ of $0.25 \mathrm{M}$ Tris- $\mathrm{HCl}, \mathrm{pH} 8.0$ followed by heating at $60^{\circ} \mathrm{C}$ for $10 \mathrm{~min}$ to minimize the effect of deacylating agents in the CAT assay. ${ }^{17}$ The CAT assay was performed essentially as described. ${ }^{16}$

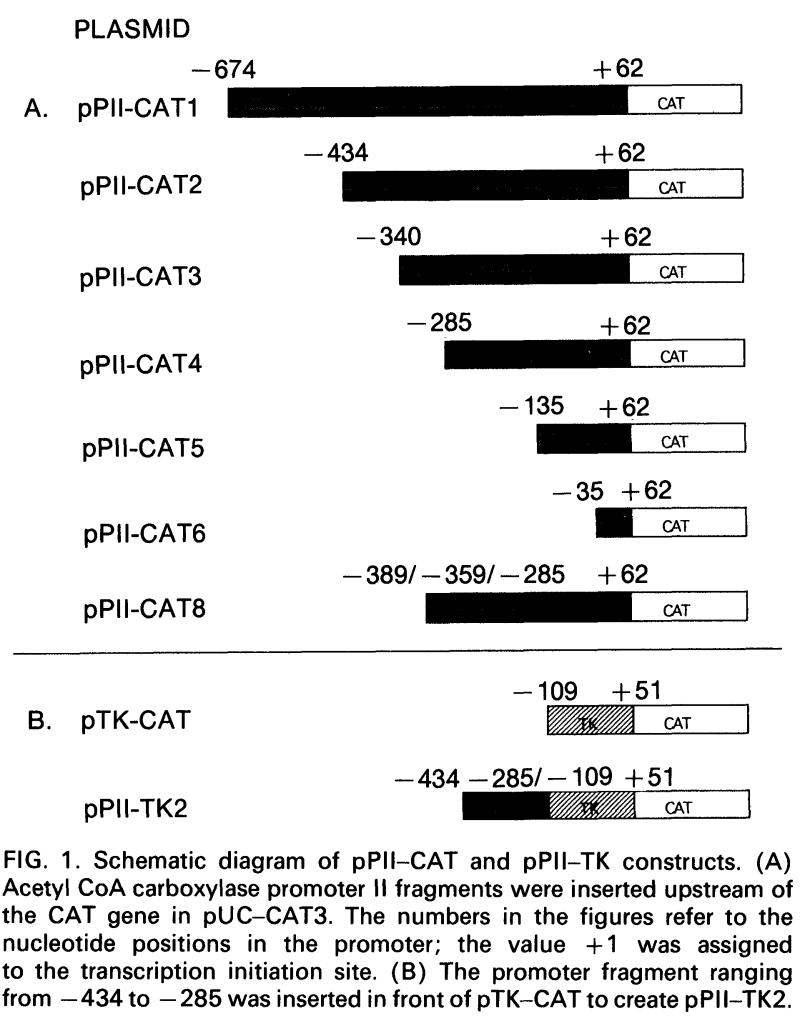

Protein amount was determined using the Bradford reagent with bovine serum albumin as the standard. ${ }^{14}$ CAT activity was expressed as percentage chloramphenicol acetylated per $\mathrm{h}$ per $\mathrm{mg}$ protein. A beta-actin-CAT construct ${ }^{18}$ was included in each experiment to correct for any differences in transfection efficiency.

Preparation of nuclear extracts: Nuclear extracts were prepared according to the method of Dignam et al. ${ }^{19}$ $30 \mathrm{~A} 5$ cells at $\mathrm{D}+4$ which were fully differentiated by the cAMP pretreatment differentiation scheme, ${ }^{14}$ or the cells at $\mathrm{D}+4$ which were kept in TNF $(200 \mathrm{U} / \mathrm{ml})$ during the same differentiation scheme, were used for preparations. Nuclear extracts were divided into small aliquots, quickly frozen in liquid nitrogen and stored at $-80^{\circ} \mathrm{C}$.

DNA mobility shift assays: For oligonucleotides, both complementary single-stranded 30 -mers $(-389$ to -359) were end-labelled separately. The labelled 30 -mers were annealed in $140 \mathrm{mM} \mathrm{KCl}$ and purified by gel electrophoresis in a $20 \%$ polyacrylamide gel or by using a Chroma Spin + TE-10 column. The labelled DNA fragments were incubated with $10 \mu \mathrm{g}$ of nuclear proteins on ice for $30 \mathrm{~min}$, in $20 \mu \mathrm{l}$ of binding buffer $(5 \mathrm{mM} \mathrm{MgCl}, 5 \mathrm{mM}$ DTT, $1 \mathrm{mM}$ EDTA, $50 \mathrm{mM} \mathrm{KCl}, 10 \mathrm{mM}$ HEPES, pH 7.9, 10\% glycerol, and $1 \mu \mathrm{g}$ poly (dI.dC). For competition experiments, different molar concentrations of non-labelled specific competitors or nonspecific competitors were added to the reactions. DNA 
mobility retardation was analyzed by a $4 \%$ polyacrylamide gel electrophoresis, and autoradiography.

DNase I footprinting: The labelled probe for the DNase I footprinting analysis was PPII-TK2 which contains the ACC promoter II fragment from -434 to -285 in pTK-CAT vector using blunt-ended Sal I site. pPII-TK2 was digested with HindIII restriction enzyme, dephosphorylated with calf intestinal alkaline phosphatase, and radiolabelled by using $\left[\gamma_{-}{ }^{32} \mathrm{P}\right] \mathrm{ATP}$ and $\mathrm{T} 4$ polynucleotide kinase. The labelling was followed by EcoRI digestion. The $224 \mathrm{bp}$ labelled fragment containing the ACC promoter fragment $(-434$ to -285$)$ and $34 \mathrm{bp}$ of TK promoter sequences was isolated through electrophoresis from the gel following its separation. Five nanograms $(20000 \mathrm{cpm})$ of the labelled DNA fragment was incubated with $40 \mu \mathrm{g}$ of nuclear extracts in a binding reaction $(50 \mu \mathrm{l})$ at $0{ }^{\circ} \mathrm{C}$ for $30 \mathrm{~min}$. The binding mixture was then subjected to DNase I $(2 \mu \mathrm{l}$ of DNase I solution containing different units of the enzyme as specified) treatment at room temperature for $2 \mathrm{~min}$. The reaction was terminated by addition of $120 \mu \mathrm{l}$ stop buffer $(30 \mathrm{mM}$ EDTA, $1 \%$ SDS, $300 \mathrm{mM} \mathrm{NaCl}$ and $250 \mu \mathrm{g}$ of tRNA per $\mathrm{ml}$ ). Samples were deproteinized by extraction with phenol-chloroform-isoamyl alcohol 25:24:1), precipitated with ethanol, and loaded onto an $8 \%$ denaturing polyacrylamide gel.

\section{Results}

Identification of cis-acting DNA elements mediating TNF responsiveness: In 30A5 cells, ACC mRNA species are synthesized under the influence of promoter II (PII), one of the two promoters in the ACC gene, and no detectable ACC mRNA species are synthesized from promoter $\mathrm{I}^{13}$ TNF inhibits the rate of transcription of the ACC gene during the transformation of $30 \mathrm{~A} 5$ preadipocyte to adipocytes. ${ }^{10}$

A series of $5^{\prime}$ deletion mutants in which deleted fragments of ACC promoter II were fused upstream of the CAT gene ${ }^{12}$ was prepared as shown in Fig. $1 \mathrm{~A}$, and the effect of the promoter II fragment on CAT gene expression was assessed in a transient expression system (Fig. 2). The data indicate that there are several regions within the -674 to +62 sequences important in the expression of the ACC gene (Fig. 2). The -674 to -434 region appeared to contain a negative control element as CAT activity increased about three-fold when this sequence was deleted. However, the -434 to -135 region contained positive elements as evidenced by the decrease in CAT activity when these sequences were deleted. The most important positive element appeared to lie between -285 and -135 , as a

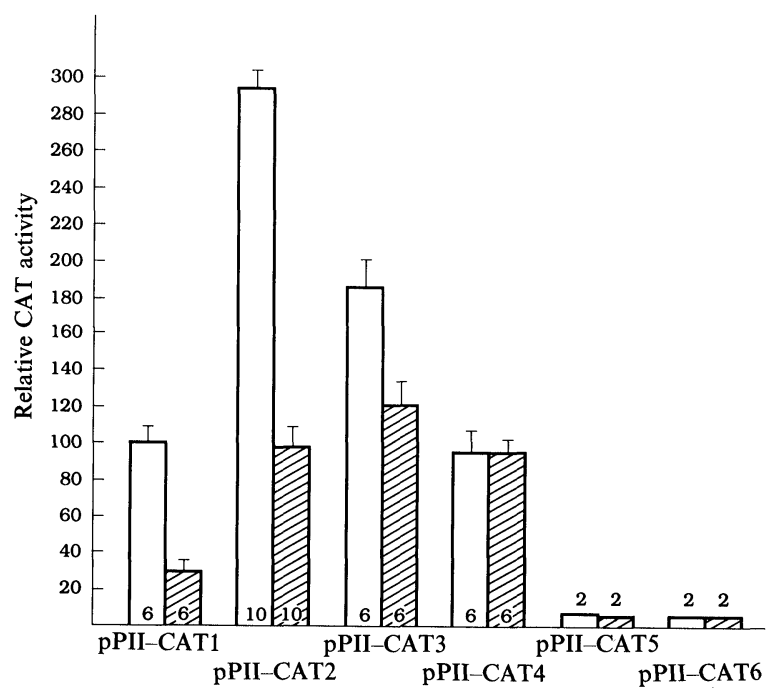

FIG. 2. Relative transcription rates of $5^{\prime}$ deletion mutants of acetyl CoA carboxylase promoter II. Various carboxylase promoter II/CAT constructs as shown in Fig. $1 \mathrm{~A}$ were transfected into subconfluent $30 \mathrm{A5}$ cells followed by a $60 \mathrm{~h}$ incubation in the absence or presence of TNF. The CAT activity obtained from pPII-CAT1 which was included in each experiment was set as $100 \%$. The number of plates used to obtain data for each bar is indicated. Error bars indicate the range of three determinations. The size of PII in each construct is: PPII-CAT1 -674/+62; pPII-CAT2, - 434/+62; pPII-CAT3, - 340/+62; pPIICAT4, $-285 /+62 ;$ pPII-CAT5, $-135 /+62 ;$ pPII-CAT6, $-35 /+62$. $\square$ Control; TNF.

greater than ten-fold decrease in CAT activity resulted when pPII-CAT4 and pPII-CAT5 were used. Recently, the authors reported the presence of a strong enhancer sequence in this region which is neither promoter specific nor orientation specific. ${ }^{12}$

To determine if TNF could suppress the expression of the CAT gene in these chimeric gene constructs, TNF was added to $30 \mathrm{~A} 5$ preadipocytes after transfection with the various constructs. Figure 2 shows that the sequences responsible for TNF mediated inhibition of ACC gene transcription do indeed lie within the -674 to +62 region. Plasmids pPII-CAT1 and pPII-CAT2 showed about $70 \%$ suppression of CAT activity upon TNF treatment in comparison to untreated controls. However, pPII-CAT4, pPII-CAT5, and pPIICAT6 did not show suppression by TNF, suggesting that the elements responsible for mediating the TNF effect may lie between -434 and -285 . To further define the role of these sequences in mediating the TNF response, we inserted a fragment spanning the $-434 /-285$ region upstream to the thymidine kinase promoter which was linked to the CAT gene (Fig. 1B). When placed distal to the thymidine kinase promoter in pTK-CAT, the $150 \mathrm{bp}$ fragment conferred TNF responsiveness to the TK promoter (Fig. 3). TNF caused about a $65 \%$ suppression of CAT activity in pPII-TK2. Previously, the authors reported that TNF treatment of $30 \mathrm{~A} 5$ cells decreased the rate of transcription of the ACC gene by 60 to $70 \%{ }^{10}$ Thus, 


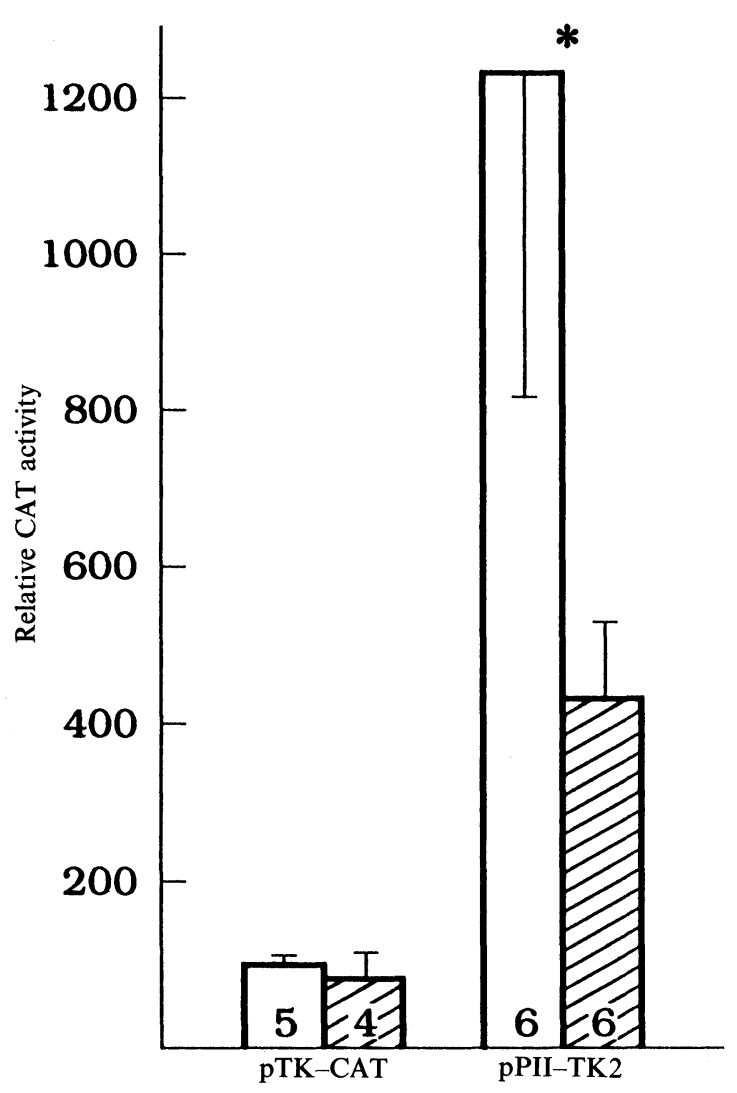

FIG. 3. Effect of acetyl CoA carboxylase promoter II sequences in a TK/CAT construct. The sequence spanning -434 to -285 was placed distal to the TK promoter in pTK-CAT to form pPII-TK2. The effect of TNF on CAT activity was assayed as described in Materials and Methods. The CAT activity obtained from pTK-CAT was set as $100 \%$. The number of plates used to obtain data for each bar is indicated. Error bars indicate the range of three determinations. Key as Fig. 2.

these experiments show that the effect of TNF is mediated by a cis element in the $-434 /-285$ region.

Nuclear proteins binding to the TNF responsive element: The -434 to -285 region and its relationship to TNF action on ACC promoter II was further characterized by determining whether specific nuclear proteins interacted with these sequences. To do this, DNase I footprinting analysis was performed using DNA fragment -434 to -285 of promoter II which was labelled at the $5^{\prime}$ end of the non-sense strand, and nuclear extracts prepared from cells with or without TNF treatment (Fig. 4). This analysis reveals that a 30 base pair from -389 to -359 of the non-sense strand was protected in the presence of the nuclear extracts from the differentiated cells (Fig. 4, lane 3) whereas the nuclear extracts from the TNF treated cells did not protect the same region (Fig. 4, lane 4). Nuclear extracts from the pre-adipocytes also did not protect the region, as shown in Fig. 4, lane 2. In order to further characterize the nuclear proteins bound to the TNF responsive region spanning -389 to -359 , the 30 base pair sequence from -389 to -359 was synthesized and the DNA mobility shift

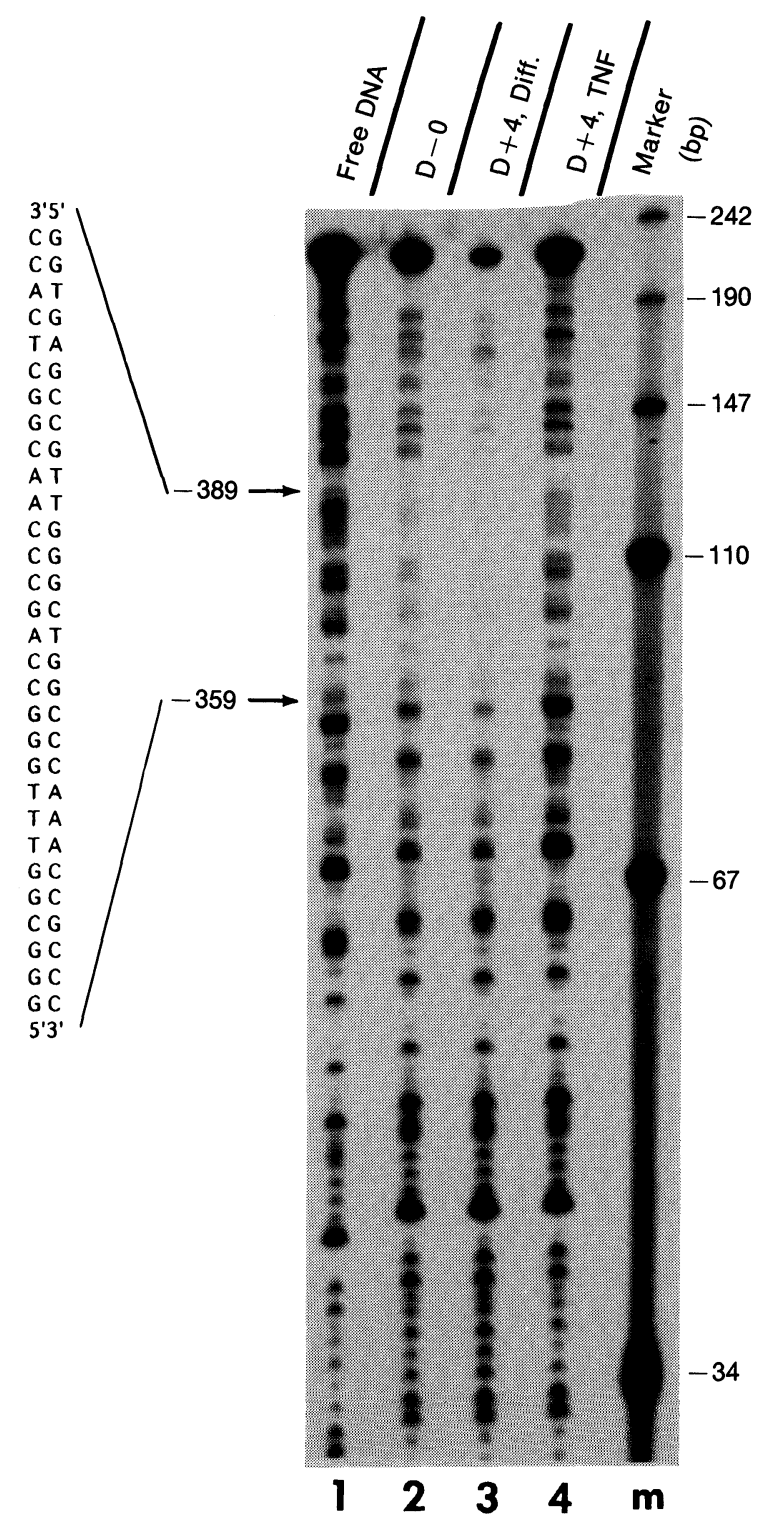

FIG. 4. DNase I footprinting analysis of DNA-protein interactions at ACC promoter II. Footprinting analysis was performed with the -434 to -285 fragment of pPII-TK2 construct labelled in the non-sense strand (lanes 1 to 4$)$. The probes were incubated with nuclear extracts $(40 \mu \mathrm{g})$ from $30 \mathrm{~A} 5$ preadipocytes at confluency (lane 2 ) or the fully differentiated adipocytes at day +4 (lane 3 ) or TNF treated cells at day +4 (lane 4 ). These binding mixtures were then subjected to DNase I $(0.5 U / 2 \mu$ for lane $1,5 \mathrm{U} / 2 \mu \mathrm{l}$ for lanes 2 through 4 ) treatment for $2 \mathrm{~min}$ at room temperature as described in Materials and Methods. Lane 1 indicates the free probe DNA. Lane $m$ represents the molecular weight markers $\left(\left[\gamma-{ }^{32} \mathrm{P}\right]\right.$ end labelled Hpall fragments of pUC 19) whose lengths in nucleotides are indicated to the right. The protected regions are indicated by arrows and the numbers correspond to the position of the nucleotides relative to the transcription initiation site. The protected sequences of the ACC PII promoter are shown in the figure.

analyses were performed (Figs 5 and 6). Four DNA bands were shifted in a sequence specific manner in the competition experiment (Fig. 5) and the formation of one of the four bands decreased when the cells were treated with TNF, as shown in Fig. 6 , lane 2. In a separate experiment, it was determined that bands 1 and 2 are due to the binding of Sp1 to the 30-mer probe (data not shown). 


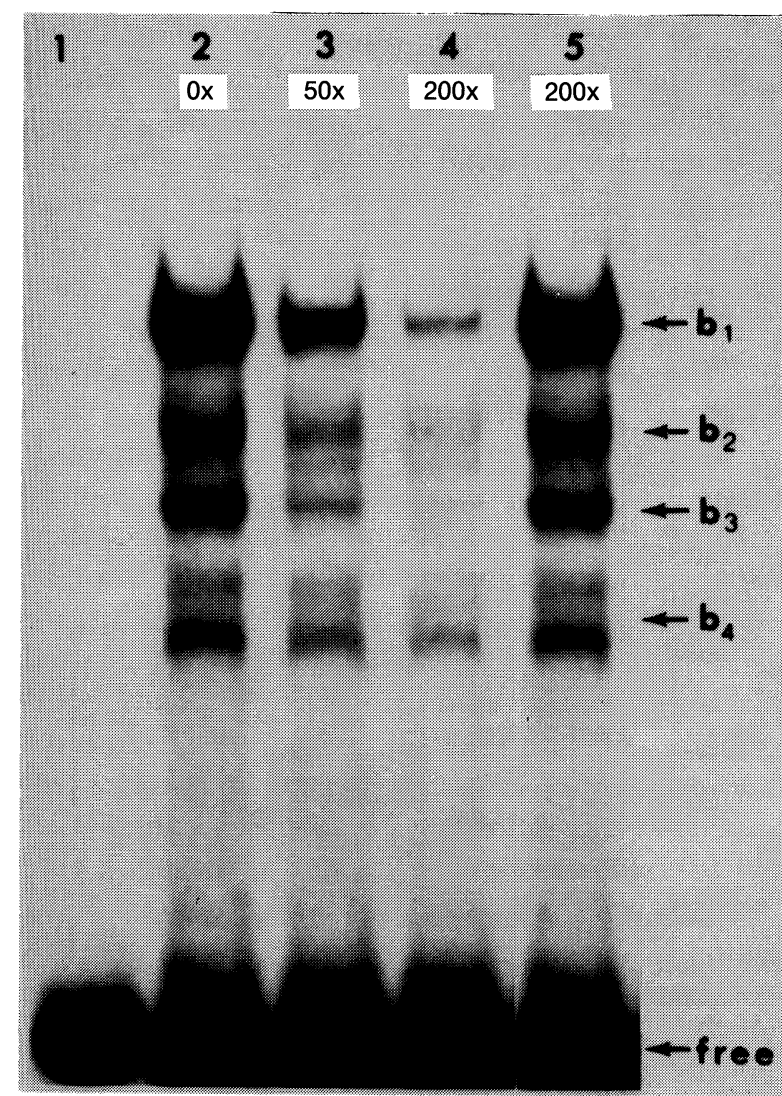

FIG. 5. DNA mobility shift binding profile. The ACC promoter II fragment spanning from -389 to $-\mathbf{3 5 9}$ was end labelled and used for the binding assays as described in Materials and Methods. The nuclear extracts from differentiated $30 A 5$ cells $(D+4)$ were added to the binding reactions The molar excess of unlabelled competitor DNA in the binding mixtures is indicated above each lane. Lane 1 , the ${ }^{32} \mathrm{P}$ labelled DNA probe; lanes 2 to 5 , the labelled 30-mer probe DNA in the presence of $30 A 5$ nuclear extracts: lanes 3 and 4 , in the presence of different amounts of the same unlabelled 30-mer; lane 5, in the presence of a nonspecific sequence (30-mer) of the ACC promoter I fragment spanning from -291 to -207.

Effect of $-389 /-359$ on TNF responsiveness: To further establish that the sequences in the $-389 /-359$ region are responsible for binding the nuclear proteins whose binding activities were diminished by the treatment of cells with TNF, the effect of the addition of the $-389 /-359$ fragment to pPII-CAT4 on the expression of CAT activity was examined (Fig. 7). The plasmid containing the 30 base pairs was prepared as follows. Plasmid pPII-CAT4 was linearized with SacI, blunt-ended by T4 DNA polymerase, and then the $-389 /-359$ fragment was inserted in the site to create pPII-CAT8 (Fig. 1A). TNF inhibited the expression of the CAT gene in plasmid pPII-CAT2 by about $70 \%$. However, CAT activity in plasmid pPII-CAT4 which does not contain the -434 / -285 region was not inhibited by TNF. However, when the $30 \mathrm{bp}$ fragment was placed in the pPII-CAT4 (pPII-CAT8), TNF responsiveness was reversed to an inhibition level of about $70 \%$. These data suggest that the sequences within $-389 /-359$ are responsible for conferring TNF responsiveness on the ACC gene. The sequence of
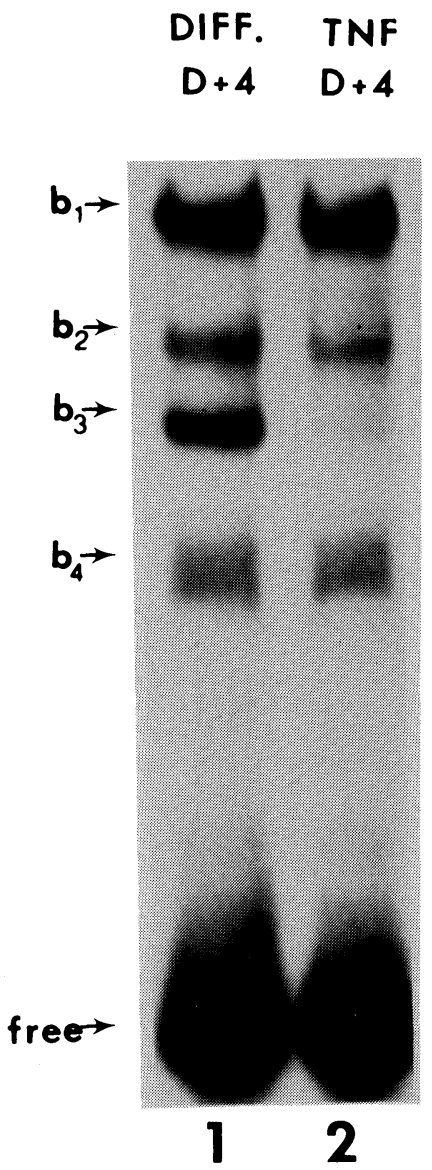

FIG. 6. DNA mobility retardation profile by nuclear proteins. End labelled 30 -mer probe $(-389$ to -359$),(0.2 \mathrm{ng})$, was incubated in the presence of nuclear proteins $(10 \mu \mathrm{g})$ on ice for $30 \mathrm{~min}$. The mobility of the retarded probe DNA was analysed through a $4 \%$ polyacrylamide gel as described in Materials and Methods. Lanes 1 and 2, labelled DNA (-389/-359) in the presence of the nuclear proteins from differentiated $30 \mathrm{~A} 5$ cells $(D+4)$ and $30 A 5$ cells treated with TNF for the same period of time $(D+4)$.

this $30 \mathrm{bp}$ region is GGTGAGCCGTTGGGCTGGCCCAAACCGCCC (Fig. 8).

Effect of the mouse TNF responsive region on TNF mediated transcription suppression: In a separate experiment, we identified a TNF responsive sequence in the mouse gene that is homologous to the rat gene. The mouse ACC promoter sequence spanning the -370 to -340 region is highly homologous to the 30 -mer sequence of the rat gene (Fig. 8). To examine whether or not the mouse sequence $(-370$ to -340) also shows TNF mediated transcription suppression, the synthesized mouse 30-mer was inserted in pPII-CAT4 vector which was linearized with SacI and blunt-ended to construct pPII-CAT4 mTNF No. 3 (right orientation) and No. 22 (opposite orientation). We examined the effects of TNF on two constructs with the 30-mer in either direction as shown in Fig. 9. In comparison to pPII-CAT4 as a negative control and pPII-CAT 2 as a positive control, TNF inhibited the expression of the CAT gene by about $60 \%$ with both the mouse constructs. These results show that the mouse 


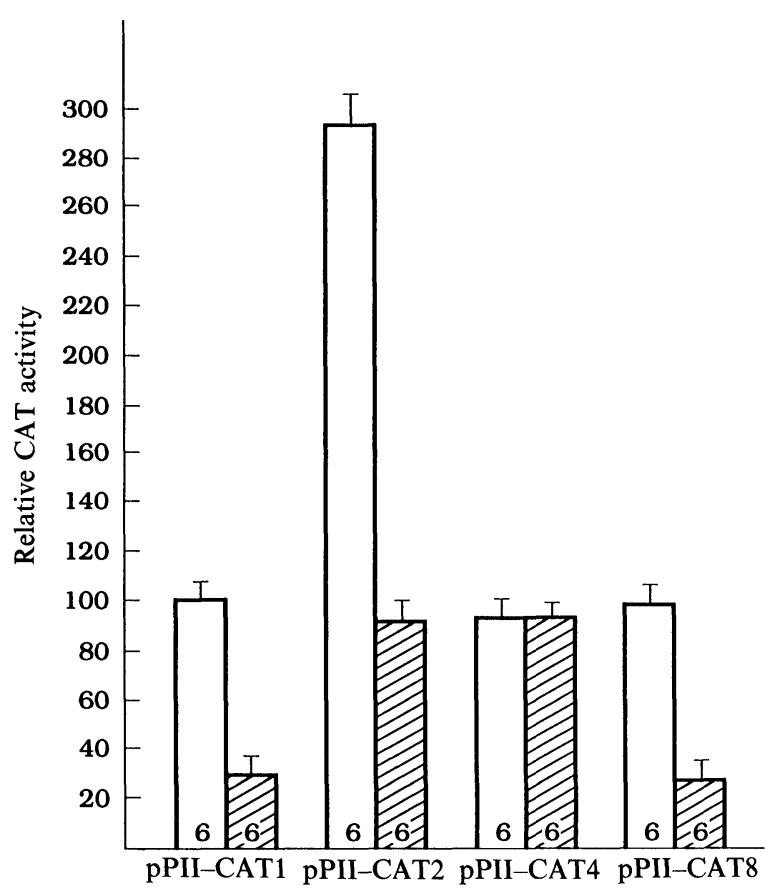

FIG. 7. Effect of the 30-mer cis element $(-389 /-359)$ on TNF action The constructed plasmid (pPII-CAT8, Fig. 1A) containing the fragment $(-389 /-359)$ at the position - 285 (pPII-CAT4) was transfected into $80-90 \%$ confluent $30 A 5$ cells. The cells were harvested for CAT assay after $60 \mathrm{~h}$ of incubation in the presence or absence of TNF. The CAT activity obtained from pPII-CAT1 which was included in each experiment was set as $100 \%$. The number of plates used to obtain data for each bar is indicated. Error bars indicate the range of three determinations. Key as Fig. 2.

$$
\text { Rat: } \quad(-389) \text { GGTGAGCGTTGGCTGGCCAAACCGCCC }(-359)
$$

FIG. 8. TNF responsive sequences rat and mouse.

sequence also effectively mediates TNF effect on the gene expression in spite of minor differences in sequence from that of rat.

\section{Discussion}

The effect of TNF on 30A5 preadipocytes has proved extremely useful for detailed study of ACC gene expression and thus, for elucidating the underlying molecular mechanisms for TNF action. Several investigators have studied the effect of TNF on lipogenic genes in various preadipocyte cell lines and in all cases TNF has been shown to inhibit the expression of this class of genes as determined by measuring their respective mRNA amounts. ${ }^{4,20,21}$ In some cases, direct measurement of transcription rates by either labelling cellular RNA or nuclear run-off transcription assays reveals that the decrease in the amount of mRNA for the lipogenic gene under study is due to inhibition of gene transcription. ${ }^{10,21}$ Such studies suggest that TNF response elements exist at the $5^{\prime}$ end of these lipogenic genes to confer TNF mediated inhibition

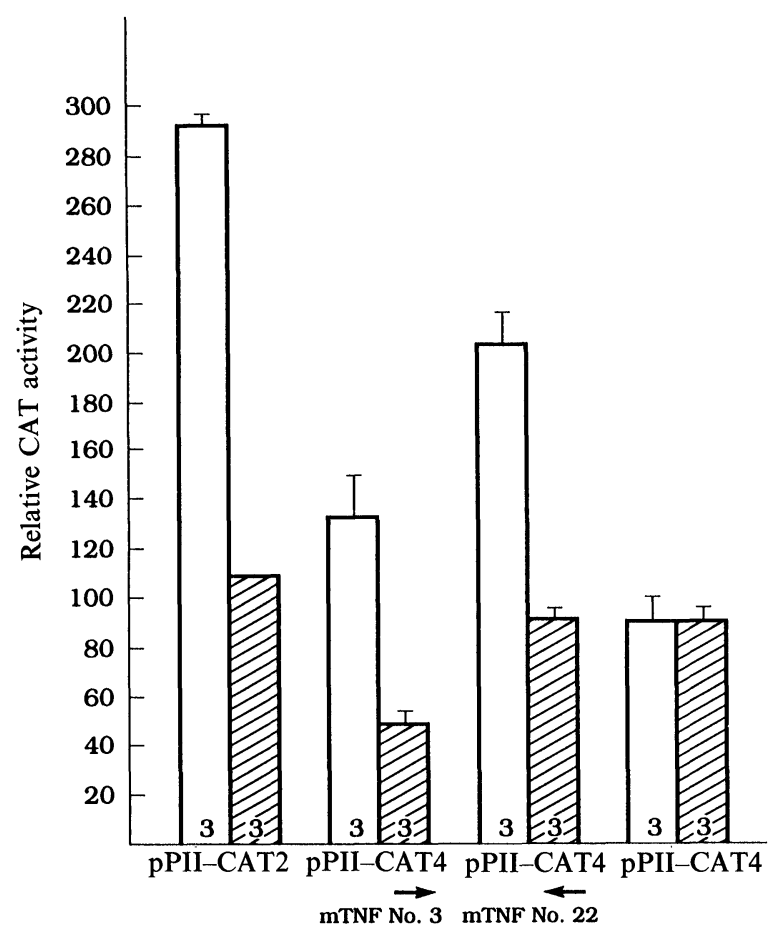

FIG. 9. Effect of the mouse TNF responsive region on expression of ACC-CAT construct. Two mouse constructs, pPII-CAT4 mTNF No. 3 and No. 22, were transfected into $80 \%$ confluent $30 A 5$ preadipocytes together with pPII-CAT2 and pPII-CAT4. Sixty hours later, CAT activities in cell lysates were assayed. The CAT activity of pPII-CAT1 included in this experiment was taken as $100 \%$. Error bars indicate the range of three determinations. Key as Fig. 2.

of transcription. The authors provide evidence that such elements do exist in at least one lipogenic gene, i.e. the ACC gene, and these elements can confer TNF responsiveness to a non-lipogenic promoter.

Construction of $5^{\prime}$ deletion mutants of ACC promoter II placed upstream of the CAT gene revealed that the -434 to +62 region inhibited CAT activity approximately $70 \%$ upon TNF treatment in comparison to controls. Further deletions appeared to limit the TNF response as the -340 to +62 construct only suppressed CAT activity by about $30 \%$. In many different experiments, we have observed that TNF can suppress about $30 \%$ of any gene construct irrespective of the nature of the promoters. These observations suggest that TNF action independent of the cis acting sequences in the promoters may still exist. These observations together with the results reported in this paper, suggest that the effect of TNF is mediated through multifaceted events. One of these is mediated through the cis acting elements in the promoter, in this case, ACC promoter II in combination with nuclear trans acting factors.

TNF treatment of $30 \mathrm{~A} 5$ cells reduces the specific binding of nuclear proteins to the $-389 /-359$ region of ACC promoter II. Whether the reduced binding is the result of a decrease in the amount of these factors, or some post-translational modification, is currently under study. The nature of these 
trans acting factors is unknown; a careful search for consensus sequences of known transcription factors $^{22-24}$ does not reveal strong homologies. In addition, a homology search for the $5^{\prime}$ ends of other lipogenic genes also yields minimal homology. Thus, the transcription factors responsible for mediating the TNF responsiveness of ACC promoter II may be novel in both sequence specificity and/or regulatory properties.

Repression of a eukaryotic gene can occur through induction of repressor, or conformational changes in activator molecules, i.e. glucocorticoid receptor molecules bound to the glucocorticoid responsive element in the promoter region. During the action of TNF, it is found that the nuclear binding proteins on the 30-mer region diminished either through modification or a decrease in their amount. A simply hypothesis is that the binding of the nuclear protein is essential for activation of the ACC gene, the promoter, and that a decrease in binding activity results in repression. However, such regulatory mechanisms are rare. Recently, Brennan et al. ${ }^{25}$ reported that serum, which inhibits myoblast differentiation, and thus various associated aspects of phenotypic gene expression, diminished the in vitro DNA binding activity of myogenin, suggesting that serum inhibition of myogenesis is due to the attenuation of the DNA binding activity of myogenin.

The underlying mechanism(s) for the decrease in the binding activities in the present case, or the effect of serum on myogenesis, ${ }^{25}$ is not known, although a mechanism such as covalent phosphorylation can easily be envisaged.

\section{References}

1. Beutler B, Mahoney J, Le Trang N, Pekala P, Cerami A. Purification of cachectin, a lipoprotein lipase-suppressing hormone secreted from endotoxin induced RAW 264.7 cells. J Exp Med 1985; 161: 984-995.

2. Oliff A, Defeo-Jones D, Boyer $\mathrm{M}$, et al. Tumours secreting human TNF/cachectin induce cachexia in mice. Cell 1987; 50:55-63.

3. Oliff A. The role of tumour necrosis factor (cachectin) in cachexia. Cell 1988 54: 141-142.

4. Min HY, Spiegelman BM. Adipsin, the adipocyte serine protease: gene structure and control of expression by tumour necrosis factor. Nucl Acid Res 1986; 14: 8879-8892.

5. Pape ME, Kim KH. Effect of tumour necrosis factor on acetyl-CoA carboxylase gene expression and pre-adipocyte differentiation. Mol Endocrinol 1988; 2: 395-403.
6. Patton JS, Shepard HM, Wilking $\mathrm{H}$, et al. Interferons and tumour necrosis factors have similar catabolic effects on 3T3-L1 cells. Proc Natl Acad Sci USA 1986; 83: 8313-8317.

7. Torti FM, Beutler B, Cerami A, Ringhold GM. A macrophage factor inhibits adipocyte gene expression: an in vitro model of cachexia. Science 1985; 229 867-869.

8. Torti FM, Torti SV, Larrick JW, Ringhold GM. Modulation of adipocyte differentiation by tumor necrosis factor and transforming growth factor beta. J Cell Biol 1989; 108: 1105-1113.

9. Lane MD, Moss J, Palakis SE. Acetyl-coenzyme A carboxylase. Curr Top Cell Regul 1974; 8: 139-195.

10. Pape ME, Kim KH. Transcriptional regulation of acetyl coenzyme A carboxylase gene expression by tumour necrosis factor in $30 \mathrm{~A} 5$ preadipocytes. Mol Cell Biol 1989; 9: 974-982.

11. Luo X, Park K, Lopez-Casillas F, Kim KH. Structural features of the acetyl-CoA carboxylase gene: mechanisms for the generation of mRNAs with $5^{\prime}$ end heterogeneity. Proc Natl Acad Sci USA 1989; 86: 4042-4046.

12. Luo X, Kim KH. An enhancer element in the house-keeping promoter for acetyl-CoA carboxylase gene. Nucl Acids Res 1990; 18: 3249-3254.

13. Pape ME. Ph.D. thesis submitted to Purdue University, West Lafayette, IN 1989.

14. Park K, Kim KH. Regulation of acetyl-CoA carboxylase gene expression. J Biol Chem 1991; 266: 12249-12256.

15. Maniatis T, Fritsch EF, Sambrook J. Molecular Cloning: A Laboratory Manual. Cold Spring Harbor Laboratory. Cold Spring Harbor, NY 1982.

16. Gorman CM, Moffat LF, Howard BH. Recombinant genomes which express chloramphenicol acetyltransferase in mammalian cells. Mol Cell Biol 1982; 2 1044-1051.

17. Crabb DW, Dixon JE. A method for increasing the sensitivity of chloramphenicol acetyltransferase assays in extracts of transfected cultured cells. Anal Biochem 1987; 163: 88-92.

18. Fregien N, Davidson N. Activating elements in the promoter region of the chicken beta-actin gene. Gene 1986; 48: 1-11.

19. Dignam JD, Lebovitz RM, Roeder RG. Accurate transcription initiation by RNA polymerase 2 in a soluble extract from isolated mammalian nuclei. Nucl Acids Res 1983; 11: 1475-1489.

20. Dobson DE, Groves DL, Spiegelman BM. Nucleotide sequence and hormonal regulation of mouse glycerophosphate dehydrogenase mRNA during adipocyte and muscle cell differentiation. I Biol Chem 1987; 262: 1804-1809

21. Zechner R, Newman TC, Sherry B, Cerami A, Breslow JL. Recombinan human cachectin/tumour necrosis factor but not interleukin-1 $\alpha$ downregulates lipoprotein lipase gene expression at the transcriptional level in mouse 3T3-L1 adipocytes. Mol Cell Biol 1988; 8: 2394-2401.

22. Reynolds GA, Basee SK, Ooborne TF, et al. HMG CoA reductase: A negatively regulated gene with unusual promoter and $5^{\prime}$ untranslated region. Cell 1984; 38: 275-285.

23. Singer-Sam J, Keith DH, Tani K, et al. Sequence of the promoter region of the gene for human X-linked 3-phosphoglycerate kinase. Gene 1984; 32: $409-417$.

24. Wingender E. Compilation of transcription regulating proteins. Nucl Acids Res 1988; 16: 1879-1902.

25. Brennan TJ, Edmonson DG, Li L, Olson EN. Transforming growth factor $\beta$ represses the actions of myogenin through a mechanism independent of DNA binding. Proc Natl Acad Sci US A 1991; 88: 3822-3826.

ACKNOWLEDGEMENTS. This work was supported by Public Health Service grant CA 46882 from the National Institutes of Health. This is journal paper number 12651 from the Purdue University Agriculture Experiment Station.

Received 25 March 1993; accepted after revision 20 April 1993 


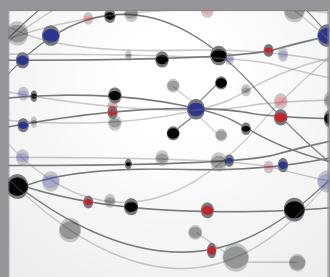

The Scientific World Journal
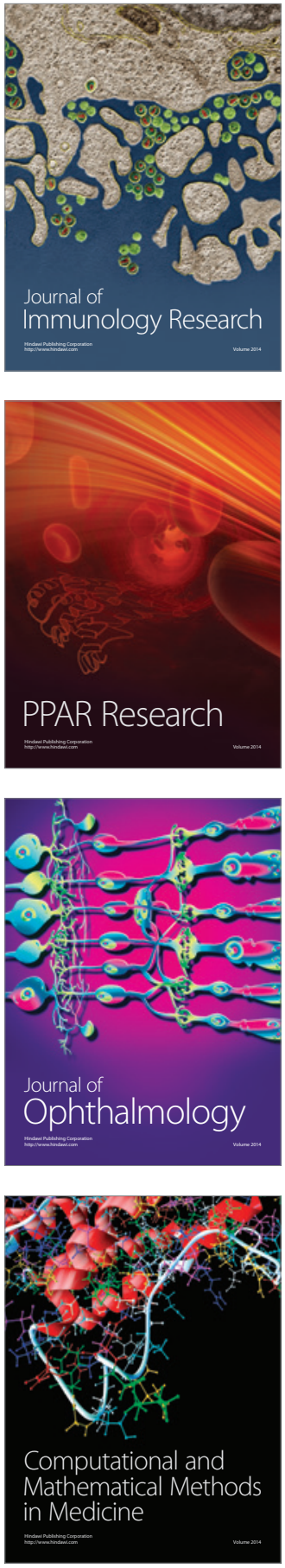

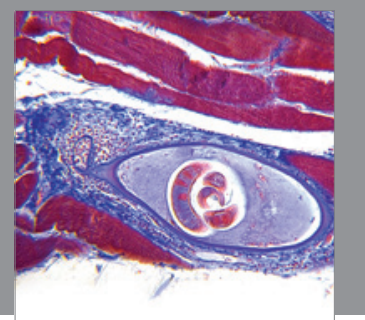

Gastroenterology

Research and Practice
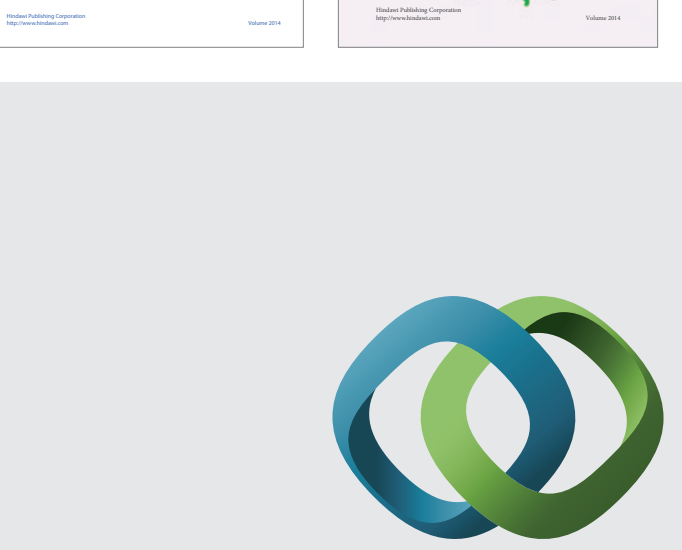

\section{Hindawi}

Submit your manuscripts at

http://www.hindawi.com
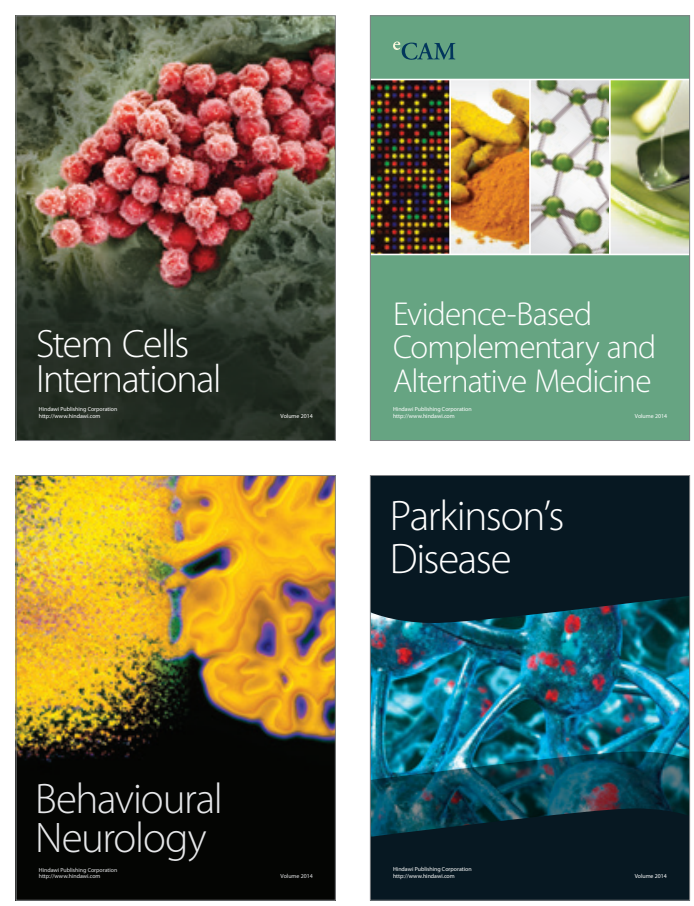

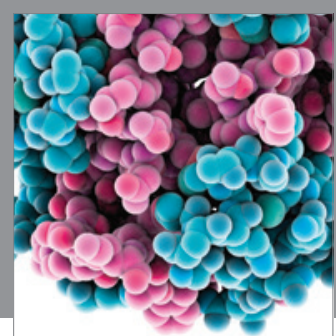

Journal of
Diabetes Research

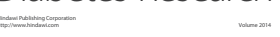

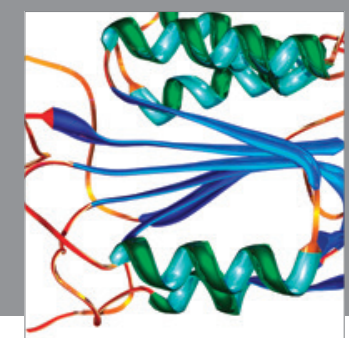

Disease Markers
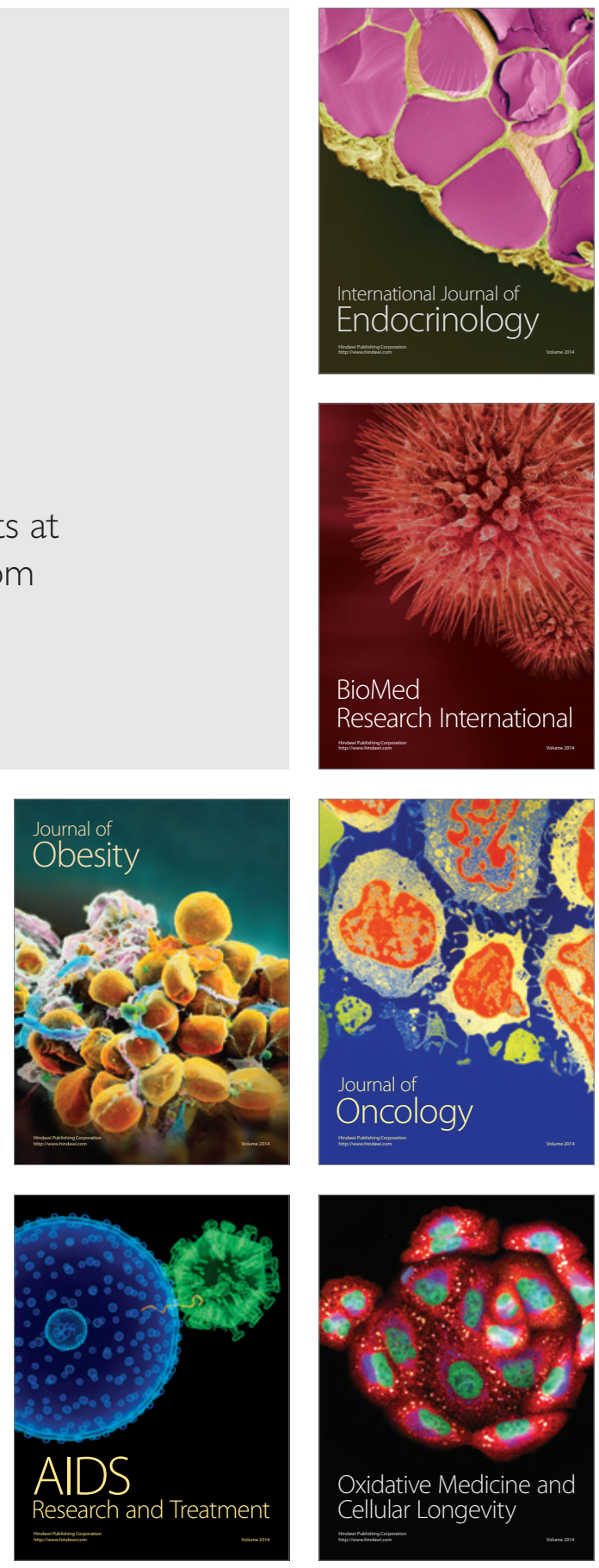